\title{
SINDICALISMO, SUPERPOPULAÇÃO RELATIVA E ForMAS DE LUTA No BRASIL E NA ARGENTINA
}

\author{
Davisson C. C. de Souza*
}

Resumo O artigo analisa a relação entre o movimento sindical e os desempregados no Brasil e na Argentina, de 1990 a 2002, a partir de uma reflexão sobre as duas principais centrais sindicais de cada país: a Central Única dos Trabalhadores (CUT) e a Força Sindical (FS), no caso brasileiro; a Confederación General del Trabajo (CGT) e a Central de los Trabajadores de la Argentina (CTA), no caso argentino. Como marco teórico, parte principalmente da teoria da superpopulação relativa de Marx e analisa como os vínculos entre o sindicalismo e os trabalhadores sem emprego contribuem para explicar, de maneira mais ampla, a unidade e fratura entre o exército de operários ativo e o exército de operários de reserva.

Palavras-chave Sindicalismo; desemprego; movimento de desempregados; superpopulação relativa; Brasil e Argentina.

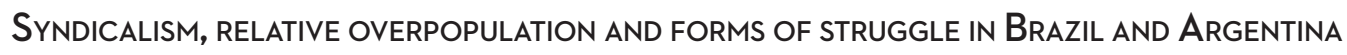

Abstract The article analyses the relationship between the unions and the unemployed in Brazil and in Argentina from 1990 to 2002. It bases in a reflection about the two main unions of each country: the Central Única dos Trabalhadores (CUT) and the Força Sindical (FS), in the case of Brazil; the Confederación General del Trabajo (CGT) and the Central de los Trabajadores de la Argentina (CTA), in the case of Argentina. It parts of the relative overpopulation theory of Marx and analyzes how the links between trade unionism and unemployed workers contribute to explain, so broader unity and fracture between the army of workmen active and reserve army of workers. Keywords Trade unionism; unemployment; unemployed movements; relative overpopulation; Brazil and Argentina.

* Doutor em Sociologia pela Universidade de São Paulo (USP) e professor adjunto do Departamento de Ciências Sociais da Universidade Federal de São Paulo (UnIFEsP). 


\section{INTRODUÇÃO}

O objetivo deste artigo é apresentar parte dos resultados da tese de doutorado precedente, em que foi estudada a relação entre sindicalismo e desempregados no Brasil e na Argentina de 1990 a 2002 (SouzA, 2010). Nesta pesquisa, observaram-se as ações e representações das principais centrais sindicais de cada país: a Central Única dos Trabalhadores (CUT) e a Força Sindical (FS), no caso brasileiro; a Confederación General del Trabajo (CGT) e a Central de los Trabajadores de la Argentina (CTA), no caso argentino.

O marco teórico foi construído especialmente a partir da tese da superpopulação relativa desenvolvida por Engels, em A situação da classe trabalhadora na Inglaterra (ENGELS, 2008), e aprofundada por Marx no capítulo 23 de O capital (MARx, 1982). Assim, o vínculo entre o movimento sindical e os trabalhadores sem emprego foi pensado a partir de um recorte mais amplo: a relação de unidade e fratura entre o exército de operários ativo (EOA) e o exército de operários de reserva (EOR).

A comparação entre o Brasil e a Argentina ocorreu a partir de uma pesquisa de campo que contou com quarenta e oito entrevistas com sindicalistas e dirigentes de movimentos de desempregados, além da leitura de documentos de fonte primária (especialmente boletins, revistas e resoluções de congressos) das quatro centrais citadas. O exercício proposto no presente texto é apresentar de maneira sintética as principais reflexões feitas acerca das duas questões centrais da tese: (i) como compreender a relação entre o movimento sindical e os desempregados, construída nos dois países no período estudado; e (ii) de que maneira esse vínculo expressou a unidade e fratura entre o EOA e o EOR.

Ao longo da tese, buscou-se situar essas perguntas em um quadro no qual foram considerados, entre outros elementos, a estrutura social, a correlação de forças, as experiências de luta e as tradições organizativas das formações sociais estudadas ${ }^{1}$. Serão revistos alguns tópicos que contaram com maior fundamentação no material de pesquisa: (i) a ideologia político-sindical predominante nas centrais analisadas e o modelo de relação do sindicalismo com o Estado e a classe capitalista; (ii) a posição adotada pelas entidades diante do neoliberalismo; (iii) suas práticas diante da estrutura sindical; (iv) os interesses imediatos de sua base; (v) e os interesses organizacionais de suas cúpulas. Em seguida, será realizada uma

1 Alguns elementos desse quadro analítico foram desenvolvidos em Souza (2009a). 
discussão sobre como esses elementos possibilitam uma reflexão mais geral sobre as formas de luta da superpopulação relativa nos dois países.

\section{SINDICALISIMO E DESEMPREGADOS NO BRASIL E NA ARGENTINA}

As práticas das centrais podem ser explicadas, em parte, por sua ideologia político-sindical, esta entendida em seu vínculo com a correlação de forças, as experiências históricas e as tradições do movimento operário e sindical de sua formação social. No Brasil, o tipo de política desenvolvida pelas centrais diante dos desempregados foi o resultado e um dos principais motores das transformações político-ideológicas mais gerais em direção a um sindicalismo "propositivo" e "de serviços" (autodenominado "cidadão"), posição que se tornou hegemônica ao longo do período estudado. As propostas de representação dos desempregados levadas a cabo pelas entidades foram condizentes com essa perspectiva. No caso cutista, essa orientação conviveu com a tradição classista e combativa mantida parcialmente (mas não isenta de contradições) por algumas correntes minoritárias².

Contudo, o sindicalismo propositivo possui uma matriz histórica no "democratismo", presente desde a formação da CUT, especialmente no setor "sindicalista" que originou a Articulação Sindical, setor majoritário da central. Essa ideologia se fundamenta, entre outros aspectos, na política institucionalista de "atuar por dentro" do Estado para transformá-lo. No caso da FS, o propositivismo tem sua raiz na tradição assistencialista e no governismo participacionista da central, tendência já expressiva em seus sindicatos mais importantes, como os metalúrgicos de São Paulo, antes da fundação da central. Por último, é necessário considerar que, embora tenha negado aspectos do trabalhismo populista, adaptando-o à sua adesão ao neoliberalismo, a FS preservou seu elemento básico: a busca da aliança capital-trabalho mediada pelo Estado como condição necessária para desenvolver e modernizar as relações capitalistas ${ }^{3}$.

Nesse contexto, é possível afirmar que a utilização dos recursos do Fundo de Amparo ao Trabalhador (FAT) e as Câmaras Setoriais expressaram as aspirações mais gerais das correntes hegemônicas do sindicalismo brasileiro. No caso cutista, foi, ademais, um exercício para a participação de seus quadros no aparelho estatal, o que se concretizou no nível federal após a eleição de Lula, em 2002.

2 Sobre a prática diante do desemprego realizada por sindicatos ligados a correntes cutistas minoritárias nos anos 1990 e 2000, consultar, por exemplo, o caso dos metalúrgicos de Campinas em Souza (2005).

3 Sobre a ideologia político-sindical da Força Sindical, consultar Trópia (2009). 
Na Argentina, o tipo de política levada a cabo pelas centrais também possui relativa correspondência com as divisões político-ideológicas presentes no sindicalismo do país, ainda que, em seu conjunto, as entidades e os setores internos analisados se enquadrem em diferentes correntes do peronismo. A ala majoritária da CGT se fundamenta no participacionismo-propositivo, matriz ideológica que caracteriza a ala hegemônica do movimento sindical no país desde a formação dessa central, em 1930. Esse setor se pauta, fundamentalmente, na política de "concertação", noção historicamente mais difundida no sindicalismo argentino do que no brasileiro, por ser constitutivo do "justicialismo"4.

A partir dessa prática, os sindicatos são considerados legítimos interlocutores de um "pacto social", construído em torno de uma aliança entre os trabalhadores e os capitalistas, com a intermediação do Estado, que, por sua vez, deve incorporar quadros de dirigentes em seu aparelho administrativo.

Destacam-se a seguir dois relatos que sintetizam como o movimento sindical no país concebe a ideologia política peronista: o primeiro, de um dirigente do setor telefônico, ligado à CTA, segundo o qual “(...) o movimento peronista [representa] a maioria do sindicalismo na Argentina, e essa ideologia do peronismo [é uma] ideologia de conciliação de classes, porque é a participação na combatividade" $\left(\mathrm{E}^{5}\right)$; o segundo, de um dirigente bancário, vinculado à CGT:

A Argentina teve acesso, a partir da segunda metade da década de 40 com o peronismo, a políticas de pleno emprego. E isso fortaleceu o movimento sindical, que teve um importante grau de participação na direção do Estado [...]. Esse primeiro governo peronista [o entrevistado se refere ao período de 1946 a 1955] marcou a consciência do trabalhador argentino e determinou o nível de confrontação que teve o movimento sindical argentino com todas as ditaduras de 1955 em diante (E2).

A CTA e os setores minoritários da CGT, como o Movimiento de los Trabajadores Argentinos (MTA), que atuou como corrente dissidente nos anos 1990, correspondem às frações sindicais mais ligadas a um sindicalismo confrontacionista, sem referência a estratégias classistas, já que seu horizonte político não é a superação do capitalismo.

4 Referente ao Partido Justicialista (PJ), que, juntamente com a CGT, são as principais entidades do movimento peronista.

5 Os entrevistados serão citados a partir da referência E1, E2, E3..., conforme a ordem em que aparecem no texto. 
Nesse sentido, poder-se-ia argumentar que a organização dos desempregados para a luta levada a cabo pela $\mathrm{CTA}^{6}$ foi a concretização de sua ideologia combativa, pautada na noção de que os trabalhadores devem se mobilizar para obter mais conquistas. Esse argumento, porém, não valeria para o caso do MTA, o que poderia ser explicado pelo fato de que o modelo de relação com o Estado nessa corrente também se expresse na fórmula peronista de busca de aliança dos trabalhadores com o poder político e econômico. Entretanto, como essa também é uma característica presente na CTA, a questão não se esgota nesse elemento. Por ora, pode-se afirmar que o sindicalismo praticado pela CGT no período estudado foi a consubstanciação de sua tendência concertacionista, sustentado pela busca de participação institucional no aparelho estatal e na aliança com o partido político no governo, levado ao paroxismo, quando o PJ está no poder, mas que não exclui o pacto social com a oposição.

A análise da ideologia político-sindical das centrais leva à discussão de dois problemas nos casos analisados. No Brasil, as correntes classistas e combativas da CUT não organizaram os desempregados a partir de uma luta com caráter massivo e nacional, embora defendessem a necessidade de mobilização do conjunto da classe trabalhadora. Na Argentina, o MTA, setor confrontacionista da CGT que conformou uma dissidência interna na central, ainda que tenha atuado conjuntamente com a CTA, também não organizou esse segmento dos trabalhadores.

Vejamos que outros fatores podem explicar as ausências presentes nos dois casos. No Brasil, a CUT, a maior central do país, opôs-se ao neoliberalismo. No caso argentino, a ala majoritária da CGT se constituiu como a principal base de apoio sindical do governo de Menem, quando este aplicou a plataforma neoliberal. Logo no início do período analisado, surgiram setores sindicais opositores nos dois países. No caso brasileiro, apareceu a FS para se contrapor à CUT e apoiar a política de Collor. No caso argentino, de dentro da CGT surgiram dissidências internas (CGT-Azopardo, MTA, CGT-Moyano) e uma ruptura que levou à formação da CTA. Esses setores se caracterizaram pela oposição ao neoliberalismo e às políticas de Menem e de De la Rúa. Pode-se dizer que a aliança dos governos com setores expressivos do sindicalismo foi uma condição indispensável para a implantação das políticas neoliberais nesses países, porém o apoio da ala majoritária do sindicalismo na Argentina não significa que houve menos resistência ao neoliberalismo nesse país do que no Brasil. A FS e a CGT não defenderam as políticas neoliberais

6 A CTA foi a única das centrais estudadas a organizar parte do movimento de desempregados que surgiram na Argentina no final da década 1990. A atuação da entidade ocorreu principalmente a partir da Federación de Tierra, Vivienda y Habitát (FTV). 
sem restrições. Nos dois casos, quando os interesses da base e da cúpula foram ameaçados, as entidades assumiram posturas mais combativas.

No caso do Brasil, a política da FS para os desempregados se inseriu na lógica do discurso neoliberal de "empregabilidade", o que se explica parcialmente por seu apoio ao neoliberalismo, ainda que essa defesa não tenha sido feita sem conflitos internos e momentos de descontinuidade. A CUT, embora no nível do discurso não tenha defendido abertamente a ideologia da "empregabilidade", na prática, fundamentou-se em seus argumentos para justificar a construção de políticas de serviços para os desempregados 7 . A central apresentou bandeiras alternativas de combate ao desemprego em relação às propostas pelas políticas neoliberais, denunciou os planos econômicos dos governos, mas não se propôs a organizar os trabalhadores sem emprego para a luta. Conservou, parcialmente, no nível do discurso, uma referência a um "horizonte" socialista, embora as práticas do que a central chama de sindicalismo "cidadão" tenham sido desenvolvidas mais como "terceira via" entre a social-democracia e o capitalismo neoliberal do que como superação deste último. Nesse sentido, as ações cutistas nesse campo atestaram o relativo abandono da bandeira socialista e o recuo da central diante da ofensiva do neoliberalismo. A entidade aceitou, em certa medida, o modelo de "assistência" aos desempregados, propugnado pela plataforma neoliberal, construído principalmente com base na noção de que o problema do desemprego é gerado pela inadequação entre a qualificação individual e as exigências do mercado de trabalho.

As experiências de economia solidária, consolidadas na criação da Agência de Desenvolvimento Solidário (ADS), em 1999, também expressaram essas transformações, ainda que estrategicamente tenham se justificado na central como forma de combinar as lutas históricas com as lutas imediatas da classe trabalhadora.

No caso argentino, como já foi dito, o setor majoritário da CGT aderiu aos aspectos centrais do neoliberalismo, especialmente às privatizações e à bandeira da "revolução produtiva", que fundamentava a aplicação de políticas econômicas como a sobrevalorização cambial e a diminuição das alíquotas às importações. $\mathrm{O}$ MTA e a CTA fizeram oposição a essas medidas, combatendo a venda das estatais, as propostas de flexibilização trabalhista, a abertura comercial e a "convertibilidade" (paridade entre o peso e o dólar). Para se contrapor ao modelo, o MTA defendeu políticas de geração de emprego e políticas sociais como o seguro-desemprego,

7 Essa política está expressa na fundação do Centro de Solidariedade ao Trabalhador (CST) pela FS, em 1998, e da Central de Trabalho e Renda (CTR), pela CUT, em 1999, instituições voltadas, entre outros objetivos, para a "requalificação profissional", a "intermediação de mão de obra" e a habilitação para o recebimento do seguro-desemprego. 
embora essas bandeiras também estivessem presentes na CGT, especialmente nos momentos em que a central rejeitou aspectos das reformas propostas por Carlos Menem (1989-1999) e Fernando De la Rúa (1999-2001).

A CTA apresentou, ademais, a reivindicação de uma "renda cidadã" universal. As diferentes correntes sindicais não se diferenciaram, porém, no objetivo de levar a cabo uma política nacionalista de desenvolvimento do capitalismo argentino. Pelo que foi exposto, é possível afirmar que, assim como a ideologia político-sindical e sua matriz ideológica mais geral, a maior ou menor adesão ao neoliberalismo não explica totalmente a ausência ou presença de organização dos desempregados por parte das entidades analisadas.

Vejamos se essa questão possui uma relação com o modelo de organização do sindicalismo nos dois países. No caso brasileiro, pode-se dizer que a política das centrais em relação aos desempregados possui uma correspondência direta com sua acomodação à estrutura sindical. A FS critica alguns de seus aspectos, mas defende abertamente o sindicalismo de Estado (BorTo JR., 1991). A CUT faz o discurso sobre a necessidade de seu desmonte, mas prevalece nessa central a prática sindical dentro da estrutura. Esse aspecto contribui para compreender por que o conjunto do sindicalismo cutista, incluindo os setores minoritários, não levou a cabo uma política de organização dos desempregados, ainda que tenha feito discurso sobre sua importância.

Ora, as chamadas correntes de esquerda também não estiveram imunes ao acomodamento à estrutura sindical, e por isso o corporativismo também se reproduz em seu interior como ideologia e prática hegemônica. Em dissertação de mestrado, foi possível verificar que uma importante entidade cutista herdeira do sindicalismo combativo das oposições dos anos 1970, o Sindicato dos Metalúrgicos de Campinas e Região, atualmente na Intersindical, não avançou no rompimento das amarras da estrutura sindical, entre elas, o modelo de representação corporativista (SouzA, 2005).

No caso argentino, a CGT e o MTA defendem o atual modelo de organização sindical por ramo de atividade com base na afiliação de trabalhadores empregados formalmente, assim como o conjunto do aparelho jurídico do sindicato oficial corporativo. A CTA não se opõe à estrutura sindical em sua totalidade, mas reivindica seu reconhecimento como central sindical, sob a bandeira do pluralismo no nível da cúpula e da organização de base ${ }^{8}$. Também defende a ruptura parcial

8 Na Argentina, apenas um sindicato (e uma central sindical) recebe a personería jurídica - próximo ao que se denomina no Brasil como "carta de reconhecimento". No entanto, a estrutura sindical do país reconhece entidades "simplesmente inscritas", que são permitidas por lei, embora 
com o modelo de representação, na medida em que incorpora a afiliação direta e individual que possibilita a associação de qualquer trabalhador, independentemente de seu vínculo de trabalho, e a incorporação de organizações populares em suas federações.

Desse modo, ainda que a entidade não tenha buscado romper com o conjunto do edifício corporativista estatal, sua concepção de sindicalização se constituiu, parcialmente, na superação da ideologia jurídica da forma legal do sindicato (Althusser, 1999), um dos principais obstáculos para a construção da unidade entre o EOA e o EOR.

Além das questões levantadas, vale destacar os interesses imediatos das bases e das cúpulas sindicais diante da organização dos desempregados. Os interesses da base empregada são os do EOA, para o qual, em última instância, a luta sindical é um meio para a manutenção de seu emprego e a conquista de melhores salários e condições de trabalho, e a realização desses objetivos não depende diretamente do incremento do número de trabalhadores ou da redução dos níveis de desemprego, que são reivindicações econômico-corporativas do EOR.

Seria importante indagar se o perfil da base influencia a superação dessa fratura. No Brasil, sabe-se que a CUT representa trabalhadores dos diferentes setores (agrário, industrial, comercial e de serviços, etc.) do pequeno, médio e grande capital privado e estatal. A FS atua predominantemente em sindicatos do setor privado, sendo inexpressivo em seu interior o sindicalismo do setor rural e do funcionalismo público. Na Argentina, a base social da CGT é diversa, mas essa central reúne os sindicatos de trabalhadores em empresas de capital mais concentrado, especialmente do setor industrial. No período em que atuou como setor cegetista dissidente, o MTA possuía sindicatos vinculados a setores de empresas de médio capital, embora não tenham sido inexistentes, em seu interior, entidades representantes de trabalhadores do grande capital.

A CTA representa dois sindicatos importantes do funcionalismo público e tem uma pequena inserção no sindicalismo privado. A partir do material investigado, não se evidenciou um vínculo direto entre o perfil dos representados e a política sindical para os desempregados. A pequena representatividade e a predominância de sindicatos do funcionalismo público no interior da CTA foram apontadas por alguns entrevistados da CGT como elementos que facilitaram sua política de mobilização dos desempregados. Porém, no caso cutista, apesar de o sindicalismo

não possam participar das negociações coletivas e eleger delegados no local de trabalho. A CTA reivindica que todas as entidades sindicais tenham esses direitos garantidos. 
do setor público ter sido identificado como um dos que teve maior resistência ao neoliberalismo, suas entidades não propuseram uma alternativa de política sindical para esse segmento.

Se as ações e representações para os desempregados não estão diretamente relacionadas aos interesses específicos do grupo socioprofissional, ou seja, da base sindical de representados, qual a relação entre as medidas levadas a cabo pelas centrais e os interesses organizacionais da cúpula? Essa política corresponde a suas estratégias de expansão e manutenção do poder no sindicalismo de Estado e, mais amplamente, no próprio aparelho estatal? Por que a direção de algumas entidades decidiu organizar os desempregados para a luta e outras não?

Não se trata, aqui, de fazer uma leitura "voluntarista” das práticas da direção sindical, como se esta fosse formada por um conjunto de atores que expressam vontades individuais, embora, no plano microssocial, esse fator possa estar presente. Pode-se entender os dirigentes como burocratas, na medida em que atuam como funcionários de um órgão da administração do Estado que exerce um tipo de "dominação legal" (MArTins, 1978), no sentido empregado pela análise clássica de Weber como ação racional com relação a fins. Ademais, as cúpulas ou quadros de dirigentes são portadores de relações sociais de classe. Como a inserção política desses sujeitos ocorre no nível do Aparelho Ideológico de Estado, em última instância, estes são agentes da reprodução da ideologia do Estado burguês (SAES, 1998).

Essa ideologia se pauta essencialmente no fetiche do Estado-protetor, visto como representante de todas as classes sociais, o qual se evidencia, em relação ao objeto estudado, na leitura das causas e na apresentação de propostas de solução para o desemprego, que, em todas as centrais analisadas, são canalizadas para políticas de Estado ativas (como a geração de empregos) ou passivas (a exemplo da assistência aos desempregados).

No Brasil, a política sindical para os desempregados se processou por meio da busca dos dirigentes pela gestão de verbas públicas, com base na lógica do oferecimento de serviços. Essa prática esteve subordinada ao interesse político-partidário dos quadros pela conquista de espaços institucionais. Para Oliveira (2003), a partir dos anos 1990, os sindicalistas teriam se convertido em "operadores de fundos públicos", ao manipularem verbas de previdência complementar, ativos das estatais privatizadas e recursos do FAT.

Para Boito Jr. (2002), esse processo seria uma das evidências da ascensão de um neocorporativismo societal no sindicalismo brasileiro. Ademais, ainda em relação a esse tema, há uma questão relacionada ao acomodamento dos dirigentes 
à estrutura sindical, pois o sindicalismo de Estado, ao garantir o monopólio de representação e da arrecadação financeira, não necessita dos desempregados para se manter, pois estes não contribuem financeiramente nem votam nas eleições sindicais.

Essa última observação vale também para o sindicalismo argentino e para toda a forma legal do sindicato, ou seja, sua expressão histórica como Aparelho Ideológico de Estado (Althusser, 1999). Tanto a CGT como o MTA não se interessaram pela representação direta dos desempregados, o que foi justificado por essas entidades com o argumento da prioridade da defesa de políticas de emprego, ideia que também aparece nas centrais brasileiras. Por isso, as diferenças político-ideológicas entre os dois setores não se estenderam à postura diante da estrutura sindical. $\mathrm{O}$ objetivo maior da cúpula cegetista no período estudado foi a manutenção de seu poder institucional nas negociações coletivas e na administração do sistema de saúde sindical por meio das obras sociales ${ }^{9}$, meios principais para a reprodução de seus interesses como organização.

O MTA teve como estratégia principal assumir a direção da entidade - o que, de fato, ocorreu durante o governo de Néstor Kirchner (2003-2007) para retomar o que, em sua avaliação, eram os autênticos ideais peronistas. Como explicitou um entrevistado da atual Direção Nacional da CGT, pertencente a essa corrente nos anos 1990:

Nós defendemos o modelo sindical argentino. Nós sempre dizemos que os melhores momentos dos trabalhadores foram quando o sindicalismo estava unido. Mas o objetivo [do MTA] nesse momento era se opor ao modelo econômico e recuperar a condução da Confederação [a CGT] para colocá-la a serviço de todos os trabalhadores. [Ademais,] jamais quisemos formar uma central. O objetivo era, Moyano [o líder do MTA] sempre dizia: "primeiro, recuperamos o movimento sindical, depois recuperamos a CGT, depois recuperamos o peronismo” (E3).

Diante dos interesses organizacionais mais imediatos dessas entidades, os desempregados possuíam um papel secundário. No entanto, apesar da relação de fratura entre os desempregados e a CGT e o MTA, a construção de uma unidade com esse segmento foi parte da estratégia de representação de base levada a cabo pela CTA, embora nem todas as organizações de desempregados tenham

9 As obras sociales constituem a principal referência do sistema de saúde da Argentina. Trata-se de planos administrados pelos sindicatos que fornecem atendimento médico à família dos trabalhadores formais. 
sido mobilizadas por essa central. É importante destacar, ademais, que o vínculo partidário ou sindical esteve presente na constituição e expansão da maioria das organizações. Aqui se torna relevante fazer duas observações: primeiro, que isso explica por que é mais adequado chamar esses agrupamentos de organizações político-sindicais de desempregados, e não de "movimentos piqueteiros", já que esse conceito remete ao instrumento de luta empregado em detrimento da base social; segundo, que o objetivo imediato da CTA também se aplica aos partidos de esquerda que organizaram esse segmento, pautado especialmente pela estratégia de expansão de suas entidades.

A CTA buscou representar os desempregados, aglutinando parte das organizações e contribuindo para dar impulso e atuação no plano nacional, especialmente à FTV, embora já existisse uma mobilização prévia desse agrupamento, anterior à proposta pela central. Como entidade que representa setores minoritários do sindicalismo argentino, essa foi a estratégia da CTA para se consolidar como organização com poder de convocação e mobilização massiva, condição necessária para pressionar o Estado por seu reconhecimento legal como central sindical.

Essa mesma tendência se verificou recentemente em setores minoritários do sindicalismo brasileiro dissidentes da CUT, como a Coordenação Nacional de Lutas (CONLUTAS) e a Intersindical, que, a partir da proposta de criarem uma nova entidade, debateram, a partir de 2007, se seu caráter seria de central "do mundo do trabalho", "sindical e popular" ou "de trabalhadores"10.

No caso da CUT e da FS, a mobilização dos desempregados não se constituiu como estratégia de seu aumento de poder sindical, já que este estava relativamente garantido pela estrutura oficial; no entanto, o oferecimento de serviços para esse segmento foi um dos principais meios para sua estratégia de disputa por poder político-partidário. Por isso, o conflito entre essas centrais, durante os anos 1990, restringiu-se ao âmbito sindical. No caso da CTA, teve um papel crucial sua estratégia para enfrentar o poder da CGT, garantida pela representatividade nacional de suas entidades.

\section{FORMAS DE ORGANIZAÇÃO DO EOR E RELAÇÃO DE UNIDADE E FRATURA COM O EOA}

Como foi dito, o vínculo entre o movimento sindical e os desempregados se insere em um contexto mais amplo da relação de unidade e fratura entre o EOA e o EOR. A seguir, será realizada uma breve apresentação da composição da super-

10 A união entre ambas não se confirmou, e a Conlutas criou a Central Sindical e Popular (CSP). 
população relativa e das formas de representação e organização de suas diferentes parcelas (latente, estagnada e flutuante) e camadas (pauperismo e lúmpen), bem como sua relação com o sindicalismo no Brasil e na Argentina.

No caso brasileiro, a parcela latente da superpopulação relativa é historicamente mais representativa que a argentina, até mesmo por conta de sua estrutura social, que possui uma população camponesa mais significativa. A partir dos anos 1980, o processo de expansão capitalista no campo, por meio da mecanização (expresso, atualmente, pelo crescimento do chamado "agronegócio"), fez com que um contingente significativo de trabalhadores repelidos da produção agrícola migrasse para a cidade ou se pauperizasse no campo. Essa parcela é composta, ainda, por expropriados pelo processo de concentração fundiária (como as vítimas de grileiros), pela população indígena pauperizada, por pequenos proprietários de produção familiar proletarizados, por camponeses parcialmente empregados (peões e boias-frias) e por trabalhadores em regime de escravidão.

Uma parte desses trabalhadores se organiza no sindicalismo rural, no movimento de resistência indígena, nas comunidades quilombolas, ribeirinhas e em organizações de camponeses, cuja maior expressão é o Movimento dos Trabalhadores Sem-Terra (MST). Ao longo da década de 1990, a CUT teve uma política constante de aliança com este último, apresentando a bandeira da reforma agrária como uma de suas principais propostas de combate ao desemprego. Por sua vez, como parte de sua política desde os anos 1990, o MST organizou trabalhadores urbanos desempregados para voltar ao campo, e, fruto dessa mobilização, surgiram os assentamentos "rururbanos" do Movimento dos Trabalhadores Desempregados (MTD). Este último foi fundado em 2000, na região metropolitana de Porto Alegre-RS, e, a partir de 2003, começou a atuar em diversos estados do país, passando a compor, juntamente com a CUT e o MST, a Coordenação de Movimentos Sociais $(\mathrm{CMS})^{11}$. Além disso, parte dos trabalhadores do campo é representada pela Confederação Nacional dos Trabalhadores na Agricultura (CoNTAG), que congrega os sindicatos rurais de todo o país. Essa confederação esteve filiada à CUT de $1991 \mathrm{a}$ 2009, quando se desligou da central.

Na Argentina, a parcela latente da superpopulação relativa é historicamente menos expressiva. Os setores mais significativos da população do campo estão organizados em sindicatos rurais. Ainda assim, nos anos 1990, surgiu o Movimento Campesino de Santiago del Estero (Mocase), que representa pequenos

11 Atualmente, o MTD atua em diversos estados do país, mas jamais chegou a possuir uma força política considerável no conjunto das lutas sociais do Brasil, tal como se evidenciou no movimento de desempregados argentino, na passagem dos anos 1990 para 2000. 
proprietários em processo de proletarização em uma das províncias mais pobres do país, porém essa parcela da superpopulação relativa não possui um peso político considerável no país.

A superpopulação relativa estagnada foi a que mais cresceu ao longo do período estudado, tanto no Brasil como na Argentina, com a diferença de que se trata de uma parcela historicamente maior e mais significativa no caso brasileiro, pois representa a maior parte do EOR urbano no país. Está composta, em ambos, por trabalhadores parcialmente empregados, com ocupações "irregulares" e temporárias, ambulantes e trabalhadores sem registro. No caso brasileiro, também é mais expressiva a "classe dos serviçais" (MARX, 1982, p. 512), estudada por Pochmann (2003) a partir da categoria de "agregados sociais". Do conjunto dessa parcela, surgiram no Brasil sindicatos de ambulantes (ou dos trabalhadores da economia informal) e um expressivo movimento pela moradia (sem-teto). Atualmente, o Movimento dos Trabalhadores Sem-Teto (MTST) faz parte da estrutura organizativa da CSP-Conlutas, e o Movimento Terra, Trabalho e Liberdade (MTL) está filiado à Intersindical. Durante o período estudado e especialmente em 2000, cresceu o cooperativismo no país. A CUT organizou parte desse movimento por meio da chamada economia solidária.

$\mathrm{Na}$ Argentina, a parcela estagnada foi uma das principais bases para a expansão das organizações de desempregados no país. Parte desses agrupamentos vinha de uma experiência de organização de bairro que, desde a década de 1980, lutava por melhores condições de vida, em um contexto marcado pelo crescimento da pobreza nas periferias, porém o fator fundamental para compreender a formação do movimento de desempregados nesse país foi a tradição de organização e luta de seu movimento operário (Souza, 2009b), em um contexto de desemprego crônico e pauperização.

A superpopulação relativa flutuante cresceu nas duas formações sociais, especialmente por conta das políticas neoliberais e do processo de reestruturação produtiva. Sua maior evidência está na eliminação de postos de trabalho e no crescimento do desemprego aberto. Essa parcela protagonizou processos de resistência às demissões por intermédio das organizações sindicais. No entanto, com a permanência na situação de desemprego, um segmento expressivo migrou para o "assalariamento encoberto", como ambulante, pequeno comerciante ou "agregado social”. Sua trajetória de trabalho foi marcada, a partir de então, pela alternância entre o emprego temporário, a ocupação irregular e o desemprego, processo verificado tanto no Brasil (GUIMARÃEs, 2004) quanto na Argentina (CASTILlo et al., 2006). 
A situação anterior, de predominância do emprego com contrato formal por tempo indeterminado e baixos índices de desemprego, rotatividade e assalariamento encoberto, contribui para explicar o aparecimento, na Argentina, de organizações de desempregados massivas e nacionais, bem como um significativo movimento de recuperação de fábricas que chegou a reunir cerca de cento e setenta unidades produtivas (FAJN, 2003). A organização prévia, por meio de associações de bairro e do movimento pela moradia, foi fundamental para a formação dessas experiências. No entanto, foi na organização sindical, principal mobilizadora das tradições de luta do país, que o núcleo originário encontrou seu potencial organizativo. No Brasil, embora tenha aparecido o MTD e o cooperativismo autogestionário, como demonstra o caso da Flaskô, em Sumaré-SP, esse tipo de experiência esteve menos presente. O movimento de recuperação de empresas foi aglutinado, de certa forma, pelo sindicalismo, especialmente pela CUT (cuja experiência mais notória é a da CONFORJA). Ademais, pode-se dizer que os interesses materiais de parte da superpopulação relativa flutuante no Brasil foram representados nas centrais por meio dos cursos de requalificação profissional e da intermediação do emprego da força de trabalho.

Uma parcela expressiva do EOR ainda é composta pelo lumpemproletariado e pelo pauperismo. No Brasil, ambas são mais expressivas historicamente. Ainda que esteja presente na Argentina, no caso brasileiro, é considerável a parcela da população que consegue sua sobrevivência por meio do "delito" individual (ENGELs, 2008). Entre os setores pauperizados, encontram-se moradores de rua e favelados que vivem a partir da apropriação da riqueza produzida por outros (esmola, coleta de lixo para o consumo ou a venda para a reciclagem, caridade de igrejas e ONGs, ou ainda do "benefício" do pauperismo oficial por meio de políticas focalistas do Estado, como o Bolsa-Família). O movimento sindical dificilmente aglutinou essas camadas.

Ao longo do período estudado, cresceu o pauperismo e o lúmpen na Argentina, mas estes seguem sendo menos expressivos que no Brasil. De qualquer forma, o movimento de desempregados do país recrutou camadas da classe trabalhadora em processo de pauperização, tendo sido um dos motores mais importantes do movimento a obtenção de auxílios do Estado, como o Plan de Jefas y Jefes de Hogar Desocupados ${ }^{12}$. Ademais, nessas organizações, estiveram muito presentes a organização coletiva para a produção e o consumo (com refeitórios e hortas

12 Plano de assistência aos desempregados, criado pelo governo argentino, que contemplava a entrega de subsídios monetários com contraprestação laboral em órgãos públicos. 
comunitárias) e pequenos empreendimentos autogestionários (como padarias, confecção de roupas e artesanato).

\section{CONSIDERAÇÕES FINAIS}

Ao longo deste texto, foi apresentada uma proposta de quadro explicativo que teve como maior aspiração contribuir para a compreensão de um tema que, a despeito de sua importância para o debate contemporâneo do movimento operário e sindical, ainda possui poucos estudos nas Ciências Sociais. De acordo com a perspectiva teórica adotada, as ações e representações do movimento sindical diante dos desempregados foram compreendidas como uma síntese de múltiplas determinações. Neste artigo, procurou-se articular alguns dos elementos trabalhados ao longo da tese de doutorado aqui referida, que se focou na análise de como essa questão se manifestou no Brasil e na Argentina.

O ponto de partida da pesquisa foi pautado na noção de que a construção de uma ação conjunta entre o sindicalismo e os trabalhadores sem emprego é parte da formação histórico-social das classes e da luta de classes. Nesse processo, a relação entre o movimento operário organizado sindicalmente (forma de manifestação orgânica do exército de operários ativo no capitalismo) e os desempregados (segmento mais expressivo do exército de operários de reserva) pode se expressar em uma relação de unidade ou de fratura. Marx, em O capital, apontou a importância da ação conjunta entre empregados e desempregados como ponto de partida para perturbar o funcionamento puro do movimento de oferta e demanda da força de trabalho. No entanto, tal como aponta Engels no prefácio àquela obra, têm sido frequentes na História os momentos em que os desempregados se encarregam de “decidir seu destino com suas próprias forças”.

\section{REFERÊNCIAS BIBLIOGRÁFICAS}

Althusser, Louis. Sobre a reprodução. Petrópolis, RJ: Vozes, 1999.

BoIto JR., Armando. O sindicalismo de Estado no Brasil: uma análise crítica da estrutura sindical. Campinas-SP: Editora da UnicAmP; São Paulo: Hucitec, 1991. . Neoliberalismo e corporativismo de estado no Brasil. p. 59-87. In: AraúJo, Ângela Maria Carneiro (Org.). Do corporativismo ao neoliberalismo. São Paulo: Boitempo Editorial, 2002. 
Castillo, Victoria; Novick, Marta; Rojo, Sofía; Yoguel, Gabriel. La movilidad laboral en Argentina desde mediados del decenio de 1990: el difícil camino de regreso al empleo formal. Revista de la Cepal, n. 89, p. 157-177, ago. 2006.

Engels, Friedrich. A situação da classe trabalhadora na Inglaterra. São Paulo: Boitempo, 2008.

FAJN, Gabriel (Org.) Fábricas y empresas recuperadas. Buenos Aires: Centro Cultural de la Cooperación, 2003.

Guimarães, Nadya A. Caminhos cruzados: estratégias de empresas e trajetórias de trabalhadores. São Paulo: USP, Curso de Pós-Graduação em Sociologia, Ed. 34, 2004. Martins, Heloisa H. T. de Souza. O Estado e a burocratização do sindicato no Brasil. São Paulo: Hucitec, 1978.

Marx, K. O capital. São Paulo: Abril Cultural, 1982.

Oliveira, Francisco. Crítica à razão dualista/O ornitorrinco. São Paulo: Boitempo, 2003.

Pochmann, Marcio. Sobre a nova condição de agregado social no Brasil: algumas considerações. Revista Paranaense de Desenvolvimento, n. 105, p. 5-23, jul./dez. 2003.

SAEs, Décio. O conceito de Estado burguês. p. 15-50. In: SAEs, Décio. Ensaio e democracia: ensaios teóricos. 2. ed. Campinas: UnicAmp, 1998. (Coleção Trajetória 1.)

SouzA, Davisson C. C. de. Sindicato dos Metalúrgicos de Campinas e Região diante do desemprego no período de 1990 a 2002. 2005. Dissertação (Mestrado em Sociologia) - Faculdade de Filosofia, Letras e Ciências Humanas, Universidade de São Paulo, São Paulo, 2005.

Movimento operário e sindical no Brasil e na Argentina: apontamentos para uma análise comparativa. PIMSA, Buenos Aires, DT 70, p. 53-111, 2009 a.

Tradições de luta sindical e emergência do movimento de desempregados na Argentina. Lutas Sociais, São Paulo, n. 23, p. 10-20, $2009 \mathrm{~b}$.

Sindicalismo e desempregados no Brasil e na Argentina de 1990 a 2002: unidade e fratura entre o exército de operário ativo e de reserva. 437 p. 2010. Tese (Doutorado em Sociologia) - Faculdade de Filosofia, Letras e Ciências Humanas, Universidade de São Paulo (FFLCH/USP), 2010.

TRÓPIA, Patrícia. Força sindical: política e ideologia no sindicalismo brasileiro. São Paulo: Expressão Popular, 2009. 